\title{
建筑工程管理中的全过程造价控制策略分析
}

\author{
温亚楠* \\ 北京城建华茂交通建设有限公司 北京 100024
}

\begin{abstract}
摘 要: 随着经济的快速发展，建筑业在我国国民经济中的地位越来越突出，对国民经济的整体发展发挥着不可 替代的作用, 而工程造价又贯穿于整个工程建设的过程, 而科学合理的造价对工程建设效益, 甚至对整个建筑的经济 效益都会产生积极地作用。因此，做好建筑工程管理的全过程造价控制有着非常重要的意义。基于此，本文分析了当 前建筑工程造价控制阶段存在的主要问题，并提出相应的控制对策。
\end{abstract}

关键词：建筑工程管理；全过程造价；控制策略

DOI: https://doi.org/10.37155/2661-4669-0308-45

\section{Analysis on the Whole Process Cost Control Strategy in Construction Engineering Management}

\author{
Ya-Nan Wen* \\ Beijing Urban Construction Huasheng Transportation Engineering Co., Ltd., Beijing 100024, Beijing, China
}

\begin{abstract}
With the rapid development of economy, the construction industry plays an increasingly prominent role in China's national economy and plays an irreplaceable role in the overall development of the national economy. The project cost runs through the whole process of project construction, and the scientific and reasonable cost will play a positive role in the benefits of project construction and even the economic benefits of the whole building. Therefore, it is of great significance to do a good job in the whole process cost control of construction project management. Based on this, this paper analyzes the main problems existing in the current construction cost control stage, and puts forward the corresponding control countermeasures.
\end{abstract}

Keywords: Construction engineering management; Whole process cost; Control strategy

\section{1 建筑工程管理中全过程造价控制的重要性}

1.1 全过程造价控制可以健全管理系统

建筑企业在参与真实的工程造价控制管理中，双方很容易忽视造价控制对于资金投人的影响。所以，实行工程项 目全过程造价控制可以全方位的对每个环节进行有目的、有节奏的资金规划和预算, 并加以控制。它可以有效提高公 司的经济效益, 降低成本和风险管理成本。特别是结算阶段对于工程造价管理来说是比较复杂的极端, 它包含整个项 目的造价信息 ${ }^{\left[{ }^{1]}\right.}$ 。公司实行全过程造价控制之后，不仅提高了工作人员的效率，还提高了造价控制的准确性。

\section{2 全过程造价控制有利于加强企业的经济效益}

项目的现场管理是最重要的工程基层管理部门。设置现场管理部门, 就是公司领导者对于整个项目在施工的过程 中对现场的施工管理。它是利用先进的技术一方面提高员工的管理观念, 另一方面减少企业的工程支出, 最终增加企 业的经济效益。建筑工程全过程控制是从根本上对项目全过程造价进行控制的关键部分, 在项目的施工过程中, 如果 没有按照计划控制工程造价，很容易让整个项目的管理系统失效 ${ }^{[2]}$ 。

\section{2 建筑工程全过程造价控制特点}

(1) 建筑工程全过程造价控制, 其管理贯穿全过程, 对建筑工程进行管理和规范, 包括项目决策、施工设计和施工

*通讯作者: 温亚楠, 1984.8.1, 汉族, 女, 河北唐山, 北京城建华宠交通建设有限公司经营副经理, 中级经济 师, 本科, 研究方向：建筑经济。 
管理等, 具体到招投标文件制定、建筑方案设计和竣工结算等各个部分, 都要进行有效控制; (2)建筑工程的全过程造价 控制，其目标和前提是节约资金和各项成本，通过合理手段科学分配工程建设中各种资源，使资源得到优化利用，同时 能够有效控制浪费问题和重复投资问题，保证施工企业的收益；(3)在不同的建设阶段，所采取的造价控制方法也是不同 的。要确保全过程造价控制的有效性, 就要根据各个阶段各自的特点, 针对性采取合理策略进行造价管理, 且要注意衔 接起不同阶段控制手段, 保证项目造价目标的实现; (4)在建筑工程造价控制中, 存在较多的不可控因素, 一些问题还会 因为周围情况的变化而产生。在严重的情况下，还会威胁到施工质量和施工安全，加大工程建设管理难度。

\section{3 建筑工程管理中造价控制存在的主要问题}

3.1 忽视各阶段的全过程造价控制

现阶段, 大多数的建筑企业对于工程项目的建设重点放在了工程的施工进度上, 过于追求施工工期的缩短, 忽视了 对施工管理的控制, 进而造成了管理人员和施工人员工作意识不足的现象。在实际的工作过程中没有严格按照施工规范 和流程进行操作, 对工程造价的管理和控制缺乏重视, 最终造成了建筑工程的施工成本较高, 全过程造价控制工作难以 得到有效的落实，这不仅会对建筑工程的施工效益造成影响，还会造成建筑企业的稳定发展和提升受到限制 ${ }^{[3]}$ 。

3.2 造价管理控制方式较为落后

当前工程造价管理方式较为落后, 传统的造价管控方式不能满足现代工程需求, 人力管控方式容易出现漏洞, 导 致材料资金的浪费现象频发，施工人员和监理人员的懈急也会造成造价控制问题，影响施工进度，造成施工工期延 长, 施工成本增加, 工程建设压力增大, 不利于工程健康发展 ${ }^{[1]}$ 。建筑工程造价管理控制模式还停留在人力监督管理 方式中, 缺乏先进的设备与技术, 造价管控效率较低, 管理人员大多是财务部门, 大多只是进行资金上的管控, 忽视 了人员、材料、能源等多个方面的管控, 缺乏动态监督管理, 因人为因素及自然因素导致物料损失, 施工人员责任意 识较差, 能耗较大, 诸多因素相加造成成本损失逐渐增多 ${ }^{[2]}$ 。

3.3 工程造价管理的监督机制尚不完善

建筑工程造价全过程动态控制问题, 需要良好的监督机制对造价工作的实施效果进行监督, 确保建筑企业工程造 价全过程动态控制管理工作效果的落实, 提升建筑企业的管理水平。在建筑工程实际造价全过程的动态控制管理中, 由于监督机制不健全, 给建筑企业埋下进行暗箱操作的机会, 在一些单位的竞投标中对于工程进行盲目造价, 给建筑 工程的质量带来隐患，严重影响了建筑市场工程造价管理的建设发展 ${ }^{[2]}$ 。

\section{4 提升建筑工程管理全过程造价控制的有效策略}

4.1 投资决策阶段造价控制

建筑工程项目的总体规模如何, 需要建成什么样的建筑群体是投资阶段需要反复论证的过程中, 这是由于投资决 策是控制施工项目总体造价的最重要阶段之一, 在投资决策的每一个环节过程中均决定了项目运行成本, 对建筑项 目施工周期等影响较大。因此，为了有效的提高投资效益，在有效控制项目总体设计的基础上，加强细节细化处理， 可以显著的提高造价控制成果 ${ }^{[3]}$ 。此外，在投资决策过程中，对建筑工程施工项目的人工成本控制进行监测和系统优 化, 在满足建筑施工质量的基础上尽可能的减少人工成本。在投资决策时需要充分考虑投资风险和收益, 立足于先 进、合理、全面的设计角度，进而通过决策投资控制造价成本，尽可能的避免可能出现的风险，并及时制定相应的解 决措施 ${ }^{[1]}$ 。

\section{2 招投标阶段的造价控制}

招投标阶段的造价控制主要是通过招投标的方式来将建筑工程的合同价限定在合理的范围内, 并利用合同条件来 控制造价风险。第一，应严格审核投标单位的资质，择优选择优质投标单位，避免信誉度差、施工质量低劣的施工企 业进人到投标单位行业, 尽可能避免由于施工能力不足而导致的工程质量差、工期拖延以及增加工程造价等不良影响 的出现 ${ }^{[4]}$ 。杜绝 “一级企业投标、二级企业转包、三级企业进场” 等违规情况发生; 第二, 应科学编制招标文件。招 标文件是编制工程标底的重要依据, 因此, 在编制招标文件过程中, 应全面掌握整体工程的实际情况, 科学确定施工工 期, 严格界定招标范围, 避免由于招标范围不合理而造成的工程重复计价的现象出现, 此外, 还应做好” 合同履约担 保 “约定方式，明确双方的权利与义务; 第三，应做好工程量清单的计量与编制工作。明确工程风险范围、包干费用 
内容、合同价款、材料价格、工期质量奖惩等内容 ${ }^{[5]}$ 。

4.3 设计阶段造价控制

科学合理的工程设计不但能够起到确保质量的作用，同时也能对拟建工程的造价实现良好地控制。首先，要求设 计人员在进行工程设计中采取限额设计, 通过这一方式实现对造价有效控制。设计人员充分结合拟建工程实际将其投 资额和工程量根据专业不同分解到不同领域，随后设计人员将分解到不同领域投资与工程量层层分解直到每个工程分 部, 从而最大程度地保障投资限额得到有效控制, 需要注意的是, 在进行限额设计中设计人员应将工程设计标准、工 程概预算指标以及设计规范等控制好 ${ }^{[4]}$; 其次, 在设计方案优化中, 建筑企业必须先审核拟建工程设计质量、功能等 是否达到要求, 随后组织相关人员对设计方案进行审核, 重点确认方案中各环节诸如施工技术、机械设备以及原材料 等是否仍有可优化的空间, 并对设计概算方法进行验证看是否符合相关规范, 通过这样的方式最大程度地保障工程造 价得到有效控制 ${ }^{[5]}$ 。

\section{4 建筑工程施工阶段的全过程造价控制}

施工阶段是建筑工程的核心环节, 在此阶段也是成本支出和投人的集中环节。首先, 需要对施工过程中的施工材 料和设备进行有效的控制，加强对施工材料和设备的质量管理和控制，避免因施工材料和设备的管理不当而对整体的 施工质量和进度造成影响 ${ }^{[5]}$ 。注重对施工材料的科学合理放置, 以及进行严格的管理, 加强对施工材料使用的控制, 避免出现材料浪费的情况, 增加施工中材料的支出; 同时, 需要定期对施工设备和材料进行定期的维修和保养工作, 确保施工设备的使用性能保持在良好的状态; 其次, 需要建立健全的施工管理监督机制, 对施工过程中的每个环节都 加强监管力度, 确保每一个施工环节都能够严格按照施工标准进行操作和施工, 避免工程施工中存在安全隐患, 从而 能够提高工程建设的施工质量 ${ }^{[6]}$ 。

\section{5 竣工验收阶段}

竣工验收阶段要进行资金成本支出的核算，根据合同内容分析施工是否符合设计要求，建筑工程项目用到的所有 材料是否符合项目标准, 对材料采购时的价格及优惠进行核查, 确保竣工验收的严谨性。大型的建筑工程需要进行定 期检查, 将项目分为几个部分, 按时进行项目施工进度的检验, 最终进行整个项目的查验, 确保建筑各部分都能保质 保量完成 ${ }^{[6]}$ 。如果建筑工程在施工过程中进行设计变更, 在竣工验收阶段还要进行变更方面的核查, 分析变更的合理 性，提升验收的效率。

\section{5 结语}

综上所述，在建筑工程的具体施工过程中，工程造价控制问题在建筑工程项目中始终贯穿于整个施工项目建设全 过程, 因此我们需要将造价管理工作当做一个关键点, 矢志不渝的加强对各个施工建设环节的优化, 利用有效的方法 和措施对工程造价进行控制, 从而降低建设工程的工程造价, 提高建设企业与施工企业的经济效益, 以最小的成本投 人建设出高质量的工程。

\section{参考文献:}

[1]寇美侠.建筑工程管理中全过程造价控制的对策分析 [J].建筑技术开发,2020,(19):61-62.

[2]刘颖.建筑工程管理中的全过程造价控制分析 [J]. 经济研究导刊,2020,(28):65-66.

[3]陈锦连.建筑工程管理中全过程造价控制的对策[J].建材与装饰,2020,(10):201-202.

[4]邢治国.建筑工程管理中全过程造价控制对策分析[J].全面腐蚀控制,2020,(9):46-47.

[5]严志锋.建筑工程管理中全过程造价控制的重要意义[J].建材与装饰,2020,(3):148-149.

[6]周婧.浅析建筑工程管理中的全过程造价控制[J].江西建材,2017,(23):220. 